\title{
CONSTRUINDO UM MOTOR ELETRICO DE CORRENTE CONTINUA COMO APRENDIZAGEM ATIVA DA LEI DE FARADAY
}

\author{
A. J. Santiago, A. F. Machado, C.E. Silva, L. Pinheiro, A.D. Tavares JR. \\ Instituto de Física, Universidade do Estado do Rio de Janeiro, Rio de Janeiro, Brasil
}

\begin{abstract}
Resumo
Apresentamos uma proposta de ensino na área de eletromagnetismo (motor de corrente continua - cc) com foco nas atividades práticas segundo a conceituação de Piaget, aqui extrapolada para incluir os objetos em ambientes virtuais. Montamos em sala de aula um motor elétrico de cc, para discutir conceitos da teoria eletromagnética. Realiza-se a modelagem física e sua simulação em computador utilizando o software educacional Modellus. Em ambas as situações, no laboratório didático com o objeto de estudo real, e no laboratório virtual com a simulação do objeto, os participantes mostram intenso interesse, ilustrando as potencialidades da aprendizagem ativa.
\end{abstract}

Palavras-chave: Ensino de física; Aprendizagem ativa; Experimentos em sala de aula; Software educacional Modellus; Eletromagnetismo.

*E-mail: aajsantiago@uol.com.br 


\begin{abstract}
We present a teaching proposal on electromagnetic phenomena (DC motor) with a focus on practical activities according to the concept of Piaget, here extrapolated to include the objects in virtual environments. We set up in the classroom an electric DC motor to discuss concepts of electromagnetic theory. We carried out the physical modeling and its computational simulation using the Modellus educational software. In both situations, the teaching laboratory with the real object of study, and in the virtual laboratory with the simulation of the object, the participants showed an intense interest, illustrating the potential of the active learning.
\end{abstract}

Keywords: Physics teaching; Active learning; Experiments in the classroom; Educational software Modellus; Electromagnetism.

\title{
1 Introdução
}

Diversos estudos apontam que atividades práticas são fundamentais para o ensino de ciências, por exemplo Krasilchik, 2004; Ern \& Aires, 2014; Zanon \& Freitas, 2007; Coquidé, 2008; e Henriques, Prado \& Vieira, 2014. Apesar disso, tem sido constatado que estas atividades estão praticamente ausentes no cotidiano da maioria das escolas, onde os recursos educativos mais utilizados são o livro e o caderno de anotações, apesar de não mais despertarem o interesse entre os participantes.

Este fato é particularmente preocupante quando ocorre nos primeiros contatos com a ciência, nos níveis mais básicos, pois é o momento em que se estabelecem os fundamentos da construção de uma visão científica, e de sua forma de entender e explicar o mundo (Andrade \& Massabni, 2011).

A relevância destas atividades também tem sido reconhecida pelo governo brasileiro, como podemos observar nos Parâmetros Curriculares Nacionais (PCN) para o ensino de ciências. Os PCN de ciências naturais deixam claro que são procedimentos fundamentais para o ensino da área aqueles que permitem a investigação, a comunicação e o debate de fatos e ideias, possibilitados pela observação, experimentação, comparação, estabelecimento de relações entre fenômenos ou fatos. Do mesmo modo, os PCN valorizam atitudes que podem naturalmente surgir nas atividades práticas, tais como: o incentivo à curiosidade, a interação social, o respeito à diversidade de opiniões, a persistência na busca de informações e de provas obtidas por meio de investigação (Brasil, 2000). Assim, a observação e a experimentação são indicadas pelos PCN como estratégias didáticas que auxiliam na obtenção de informação. É importante lembrar, contudo, que os PCN perderam a oportunidade de formular uma crítica fundamentada à visão puramente empirista-indutivista de ciência, e assim, podem conduzir os professores a uma interpretação errônea sobre a natureza da ciência (Pino, Ostermann \& Moreira, 2005).

Há que se notar ainda, que o jovem da geração atual, por muitos chamada de geração Y, o qual nasceu imerso num ambiente tecnológico, com todo tipo de informação literalmente disponível na palma de sua mão, se recusa a participar de uma sala de aula behaviorista. Ele quer interagir, ser autor da construção 
de seu conhecimento (Santiago et al., 2015). Esta atitude menos passiva em sala de aula, é uma clara indicação da relevância pedagógica das atividades práticas.

Assim, o objetivo do presente trabalho é relatar uma experiência bem-sucedida de aula, baseada em atividades ditas práticas, e assim conceituadas segundo a visão de Piaget.

Com efeito, na teoria piagetiana a experiência física consiste em agir sobre os objetos para abstrair conhecimentos a partir dos próprios objetos, com a presença física ou mental deste objeto (Piaget, 1972, 1978), isto é, o objeto concreto, pode estar presente fisicamente ou interiorizado na mente do sujeito; o objeto não pertence exclusivamente ao mundo material. Extrapolando a conceituação de Piaget para o mundo virtual, propomos como atividades práticas, a realização de um experimento onde o objeto tem presença física, e a sua simulação usando software onde o objeto tem presença virtual.

A ideia de utilizar softwares como ferramenta auxiliar da aprendizagem é bem antiga. Uma das primeiras utilizações foi na década de 1940, quando pesquisadores americanos desenvolveram simuladores de voo para o treinamento de pilotos. No âmbito acadêmico, o primeiro a utilizar tais ferramentas foi Burrhus Frederic Skinner (Skinner, 1972), ao introduzir as chamadas "máquinas de ensinar" para alunos das séries iniciais (equivalentes ao ensino fundamental brasileiro). Essas "máquinas de ensinar”, como ele próprio as chamava, são ferramentas que contêm um mecanismo simples de perguntas e respostas, que libera a próxima pergunta apenas quando o aluno respondesse de forma correta a anterior. Um invento simples, mas que propiciava ao aluno se auto testar, com a possibilidade de responder as perguntas, cada um no seu próprio ritmo.

Com o passar dos anos e a disseminação dos computadores, para uso público, vários softwares que antes estavam restritos somente às universidades e centros de pesquisa, começaram a ganhar mais espaço. Hoje, na era da informação e da tecnologia, onde o que há de mais moderno cabe no bolso de uma camisa, há um arsenal tecnológico disponível e já incorporado às atividades cotidianas dos sujeitos, independentemente de sua classe social e faixa etária. O uso das tecnologias de informação e comunicação (TIC) está modificando drasticamente o modelo de vida social (Machado et al., 2014). Estas tecnologias acabarão provocando uma revolução no sistema educacional, e cada vez mais, os professores estão sendo compelidos a explorar ao máximo estes recursos tecnológicos nas suas práticas pedagógicas, o que talvez, seja o caminho para despertar o interesse e a motivação discente.

Tal trabalho envolverá necessariamente a internet que permite explorar, praticamente com acesso irrestrito, ilimitado e imediato às mais variadas formas de comunicação e informação (Valente, 1998). É neste contexto, de inovação tecnológica crescente, onde realmente observa-se que os softwares educacionais também vêm crescendo em uso e sendo aprimorados, passando do simples mecanismo de perguntas e respostas para programas com interfaces contendo gráficos, animações, tabelas de dados e outras ferramentas, além de estarem disponíveis para download e com compatibilidade com os vários sistemas operacionais, que os educadores terão de dar uma resposta às demandas de uma sociedade emoldurada pela evolução tecnológica, científica e sociocultural.

Como foi referido anteriormente, o uso dos softwares educacionais nas escolas, complementa o ensino das ciências, neste caso especifico o ensino de física. Diversos autores reconhecendo esses fatos já os vêm incluindo em seus livros textos, onde os mais variados fenômenos podem ser simulados (Wentworth, 2009; da Silva, 2014).

A simulação, portanto, começa a ocupar lugar de destaque nos processos de ensino e aprendizagem, 
pois a manipulação de parâmetros, que lhe é intrínseca, permite experimentar diferentes variáveis para situações do mundo real, oferece comandos que auxiliam no estabelecimento de relações de proporção, tempo, distância e deslocamento, aspectos fundamentais para a compreensão e uso da linguagem da ciência física, não se limitando, porém, nem a esta, nem àqueles, mas operando com fronteiras móveis articuladas pelas descobertas a partir da refutação ou da corroboração das hipóteses formuladas e testadas para cada fenômeno apreciado.

Recentemente tem sido destacada a relevância e a atualidade de proposta de ensino que coloque o 'estudante em ação', com o uso de metodologias que podem ser chamadas de aprendizagem ativa (Henriques, Prado \& Vieira, 2014). Acreditamos que a atividade prática tanto em laboratório físico, através da experimentação, quanto no laboratório virtual, através da simulação, constitui importante ferramenta para a aprendizagem ativa.

É neste contexto que se apresenta, em seguida, um exemplo concreto de aula envolvendo a metodologia da atividade prática, que envolve tanto a experimentação com o objeto físico, real, quanto a simulação com o objeto virtual, e que pode proporcionar uma aprendizagem ativa. O objetivo é discutir o motor de corrente contínua por meio de atividades práticas com enfoque na aprendizagem ativa. Na seção 2, apresenta-se a teoria fundamental envolvida, a seção 3 e a 4 apresentam o experimento e o motor construído em sala de aula, respectivamente. A seção 5 traz a modelagem e a simulação. Finaliza-se com as discussões na seção 6.

\section{O REFERENCIAL TEÓRICO: LEI DE FARADAY}

No início da aula prática, aborda-se de forma resumida, o contexto histórico que envolveu o desenvolvimento do eletromagnetismo, como, por exemplo, a necessidade de transmissão de energia por longas distâncias, o aumento da potência elétrica transmitida, perdas, entre outros. A discussão inicia-se com o experimento de Hans Christian Oersted, que mostrou como os fenômenos elétricos e magnéticos estão relacionados.

Utilizando-se inicialmente de um fio condutor retilíneo, por onde passava uma corrente elétrica, Oersted posicionou sobre esse fio uma agulha magnetizada, livremente orientada na direção norte-sul.Fazendo passar uma corrente no fio, observou que a agulha sofria um desvio em sua orientação, e que esse desvio era perpendicular ao fio. Ao interromper a passagem da corrente elétrica, a agulha voltou a se orientar na direção norte-sul. Assim, ele concluiu que a corrente elétrica no fio se comportava como um imã colocado próximo à agulha magnetizada. Ou seja, a corrente elétrica estabeleceu um campo magnético no espaço em torno dela, e esse campo foi o agente responsável pelo desvio da agulha. Pode-se concluir, então, que as cargas elétricas em movimento criam numa região do espaço próximo a ela, um campo magnético.

Desta forma, o surgimento de um campo magnético, como resultado da passagem da corrente elétrica, foi exaustivamente explorado e divulgado por Oersted, em meados do século XIX. Essa descoberta reflete a evolução do longo processo histórico de estabelecimento e consolidação do eletromagnetismo (Chaib \& Assis, 2007), e foi fundamental para o atual entendimento do eletromagnetismo, em que os fenômenos elétricos e magnéticos são vistos de forma unificada. A Figura 1 ilustra uma montagem da experiência de Oersted. 


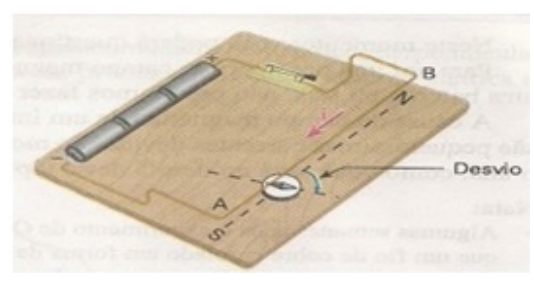

Figura 1: Experiência de Oersted.

Pouco mais de uma década após a descoberta de Oersted relacionada à produção de efeitos magnéticos por correntes elétricas, o inglês Michael Faraday, no início do século XIX, teve a curiosidade de realizar experimentos que pudessem resultar no efeito inverso, ou seja, a produção de uma corrente elétrica a partir da aplicação de um campo magnético. Realizou vários experimentos, que consistiam basicamente em circular corrente em uma bobina, produzindo assim um campo magnético, e pode verificar que uma corrente elétrica poderia ser induzida em outra bobina colocada nas proximidades da primeira.

Experimentos com bobinas concêntricas, ou com apenas uma bobina conforme ilustrado na Figura 2, entre outras configurações, foram concebidos, e em nenhum destes, Faraday pôde confirmar a geração de corrente elétrica a partir de um campo magnético estacionário. Observou, no entanto, a perturbação na agulha magnetizada de seu galvanômetro apenas durante os breves intervalos de tempo em que ligava e desligava a bobina alimentada pela bateria. Estava assim, Faraday, diante de uma das grandes descobertas da humanidade que, propriamente interpretada, implicaria no efeito, atualmente bem estabelecido, de um campo magnético variável no tempo induzir, em sua vizinhança, um campo elétrico. Esse fenômeno é a base do funcionamento de máquinas elétricas, motores e transformadores.

Esse efeito também foi demonstrado simultaneamente, e de forma independente, por Joseph Henry nos Estados Unidos e por isso é também denominado por alguns autores como lei de Faraday-Henry. Neste texto, será adotada a terminologia "lei de Faraday", que é a mais comumente utilizada na literatura.

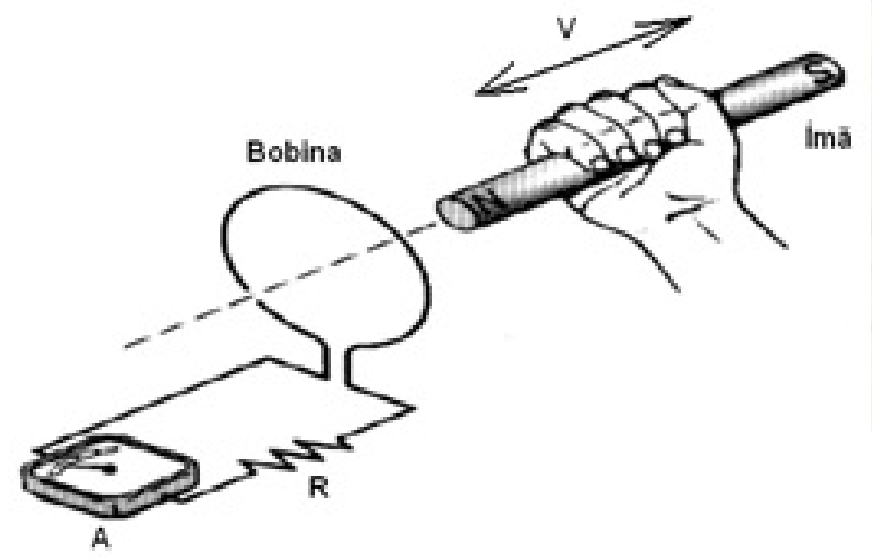

Figura 2: O ponteiro do amperímetro A sofre uma deflexão quando o ímã está em movimento em relação à bobina.

A lei de Faraday estabelece que uma força eletromotriz é gerada em um circuito elétrico fechado, submetido a um fluxo magnético variável no tempo. Esta lei, pode ser expressa em termos dos campos, 


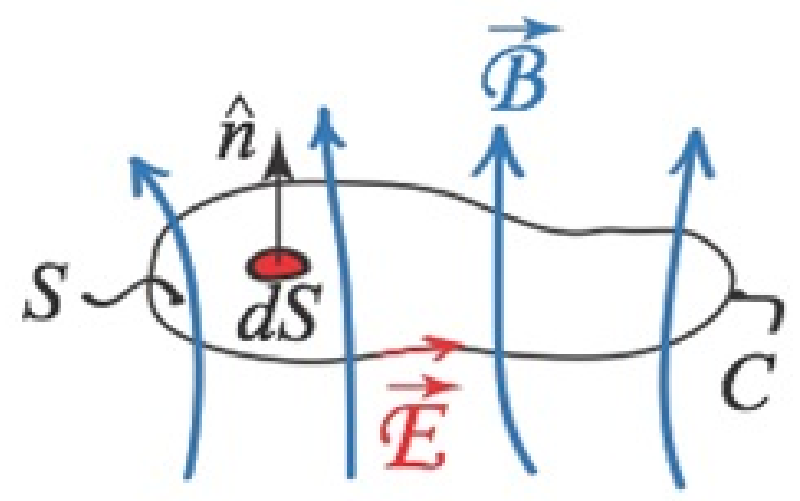

Figura 3: Configuração de circuito para a lei de Faraday.

com base na Figura 3. O caminho delimita a superfície aberta e é orientado de acordo com a regra da mão direita, de forma que o sentido do polegar é o da normal à superfície, $\hat{n}$.

O fluxo magnético através dessa superfície é representado pela integral sobre a área (envolvida por C) do produto escalar entre o campo magnético e o vetor elemento de superfície $(d \vec{S}=\hat{n} d S)$, isto é $\Phi_{B}=\int \vec{B} \cdot \hat{n} d S$.

A lei de Faraday diz que, quando o fluxo de $\vec{B}$ começa a atravessar o circuito C, um campo induzido, responsável por uma fem (força eletromotriz) no circuito, será produzido em virtude da variação do fluxo $\Phi_{B}$.O campo elétrico induzido $\vec{E}$ no elemento $d \vec{\ell}$ do circuito $C$, resultante da variação do fluxo magnético é dado por

$$
f e m=\oint \vec{E} \cdot d \vec{\ell}
$$

onde $\vec{E}$ é definido em termos da força de Lorentz, isto é, de forma que a força eletromagnética sobre uma carga de prova seja sempre a força de Lorentz. Essa redefinição de campo elétrico é necessária, uma vez que a definição usual pela lei de Coulomb é válida na eletrostática apenas.

Assim, pode-se enunciar a lei de Faraday como: 'a fem induzida em um material condutor é proporcional ao valor negativo da taxa de variação do fluxo magnético', a qual se representa como

$$
f e m=-\frac{d \Phi_{B}}{d t}
$$

Para um campo espacialmente homogêneo, $\Phi_{B}=B S \cos (\theta)$, então,

$$
f e m=-S \cos (\theta) \frac{d B}{d t}-B \cos (\theta) \frac{d S}{d t}-B S \frac{\cos (\theta)}{d t}
$$

o que mostra que uma fem pode ser induzida variando-se a intensidade do campo magnético no tempo, ou variando-se a área do circuito no tempo, ou o ângulo entre $\vec{B}$ e $\vec{S}$ no tempo, ou ainda, combinar qualquer uma destas três possibilidades. 
Tabela 1: Convenção de sinais para a indução eletromagnética.

\begin{tabular}{|c|c|c|l|}
\hline$\Phi_{B}$ & $\frac{d \Phi_{B}}{d t}$ & fem & sentido da corrente induzida \\
\hline \multirow{2}{*}{+} & + & - & horário \\
\cline { 2 - 4 } & - & + & anti-horário \\
\hline \multirow{2}{*}{-} & + & - & horário \\
\cline { 2 - 4 } & - & + & anti-horário \\
\hline
\end{tabular}

\subsection{LEI DE LENZ}

O sinal negativo da Eq. (2) não foi determinado por Faraday, ele é devido ao trabalho de Lenz, e ao que se chama de lei de Lenz: "a variação do fluxo magnético através de uma espira cria nela uma corrente elétrica induzida, de modo que essa corrente crie um campo que se oponha a variação do fluxo através da espira". Essa lei, então, diz que a fem gera uma corrente que tende a se opor à variação do fluxo, estabelecendo o sentido da corrente induzida.

A lei de Lenz reflete o princípio de conservação de energia em circuitos nos quais há corrente induzida. Com efeito, se o lado direito da Eq. (2) tivesse sinal positivo, um aumento do fluxo tenderia a aumentar ainda mais o fluxo, levando a um fluxo infinito e, portanto, a uma corrente infinita, a partir do simples movimento do magneto na direção da espira. Nota-se ainda, que o sinal da equação está relacionado à conservação de energia, mas a lei de Faraday não é consequência da conservação de energia, ela é uma lei experimental independente.

A aplicação da lei de Lenz a um circuito condutor colocado em campo magnético pode ser feita de acordo com os seguintes passos:

1. define-se a direção positiva para o vetor área $\vec{S}$;

2. admite-se o campo uniforme e efetua-se o produto escalar $\vec{B}$ e $\vec{S}$ para determinar o sinal do fluxo $\Phi_{B}$;

3. determina-se a taxa de variação do fluxo $d \Phi_{B} / d t$ que leva às três possibilidades:

$$
\begin{array}{ll}
\left(d \Phi_{B}\right) / d t<0, & \text { fem }>0 ; \\
\left(d \Phi_{B}\right) / d t=0, & \text { fem }=0 ; \\
\left(d \Phi_{B}\right) / d t>0, & \text { fem }<0,
\end{array}
$$

4. determina-se o sentido da corrente induzida com base na regra da mão direita: "com o polegar apontando na direção de $\vec{S}$, fechamos os dedos ao redor do eixo que define a direção de $\vec{S}$. A corrente induzida segue mesma direção que nossos dedos apontam ao se encurvarem, se a fem for maior que zero, e na direção oposta se $f e m<0$ ".

A Tabela 1 resume a convenção de sinais para a indução eletromagnética. 


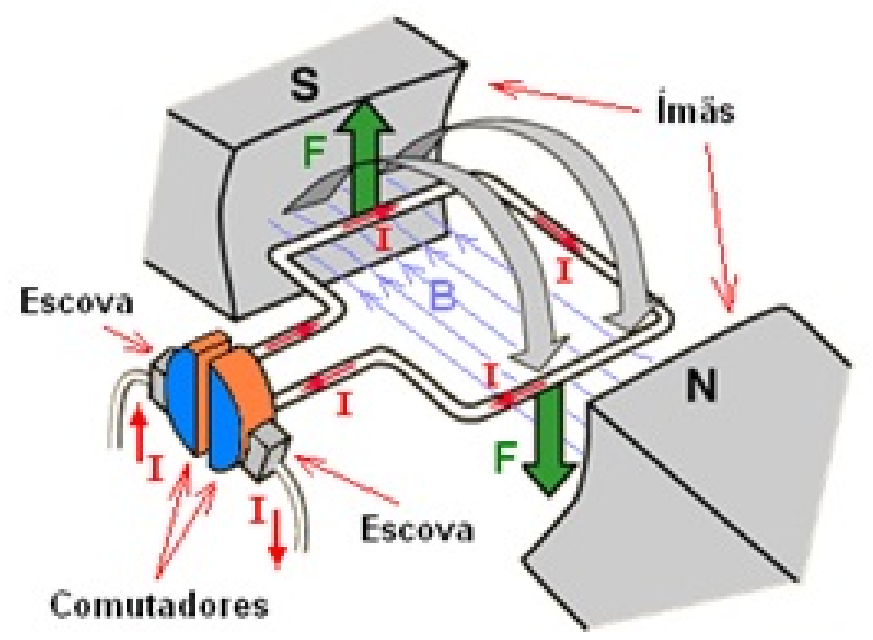

Figura 4: Princípio de funcionamento de um motor de corrente contínua. Quando circuito é ligado a uma fonte de energia elétrica, a corrente elétrica que atravessa a bobina faz surgir um campo magnético que interagirá com o campo magnético externo, surgindo, em consequência, um torque que irá fazer a bobina girar.

\section{EXPERIMENTO PARA APROPRIAÇÃO DO PRINCÍPIO DE FUNCIONAMENTO DE UM MOTOR DE CORRENTE CON- TÍNUA}

Os motores elétricos fazem parte de uma infinidade de equipamentos, desde pequenos motores que funcionam com pilhas até os grandes motores de máquinas industriais, por exemplo.

Motores são transdutores que convertem energia elétrica em energia mecânica. Nesta função, eles fazem parte de uma grande quantidade de equipamentos que encontramos no dia a dia. Atualmente, com a união cada vez maior da eletrônica com a mecânica, e o desenvolvimento de dispositivos mecatrônicos, os motores têm aparecido em quantidade cada vez maior e numa variedade de tipos até então nunca vistos.

A ideia de se obter energia mecânica a partir da energia elétrica, criando-se assim o primeiro motor de corrente contínua surgiu a partir dos trabalhos de Faraday. No entanto, naquela época, as fontes de energia elétrica eram limitadas o que fez com que este motor apenas se tornasse uma curiosidade de laboratório sem nenhuma aplicação prática imediata.

Os motores modernos se baseiam no princípio de que quando uma corrente elétrica percorre um condutor (um fio metálico, por exemplo) imerso em um campo magnético externo surge uma força perpendicular ao fio que tende a movê-lo. Se no lugar de um simples fio condutor for usada uma bobina com muitas espiras, apropriadamente disposta sobre um eixo e este sobre mancais, se o conjunto estiver imerso em um campo magnético uniforme externo, quando a bobina for percorrida por uma corrente elétrica está poderá girar devido à interação do campo magnético da bobina com o campo magnético uniforme externo. Esta ideia pode ser melhor entendida com o auxílio da Figura 4.

Quando a corrente flui pela espira cria-se em torno desta um campo magnético. Este campo magnético 


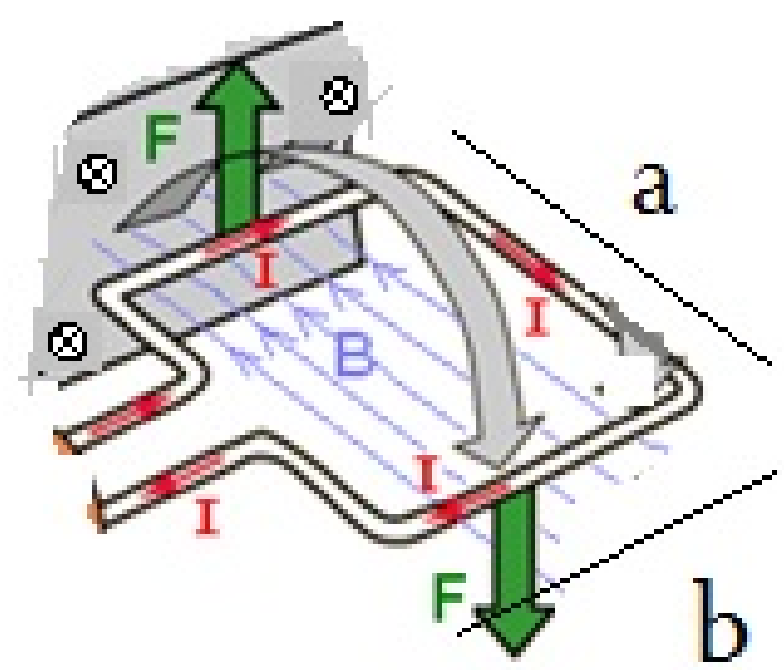

Figura 5: Espira retangular na presença de um campo magnético uniforme. O símbolo $\otimes$ indica que o sentido do campo B é perpendicular e está apontado para dentro do plano hachuriado.

interage com o campo magnético externo, gerando-se assim, um torque que faz a bobina girar. Dito de outra maneira, cada lado da espira pode ser visto como um fio condutor conduzindo uma corrente, e então, em presença de campo magnético ficará sujeito a ação de uma força magnética que é perpendicular ao plano definido pela direção do campo e a direção do fio.

Forças de mesma intensidade, mas de sentidos contrários, atuam sobre lados opostos, e estão representadas em verde na Figura 4. Nos lados maiores, a direção do fio é a mesma do campo $\vec{B}$ (admite-se que o campo só tem componente na direção indicada) e a força magnética é nula. As forças representadas na figura, embora simétricas, tem linhas de ação distintas e, então, produzem torque (indicado pelas setas curvas na Figura 4). Este torque pode ser transmitido de forma que possa fazer girar uma hélice, uma roda, uma engrenagem, etc., através do eixo sobre o qual está montada a bobina.

A modelagem deste motor pode ser feita diretamente de um experimento de Faraday, em que uma espira montada sobre um eixo, está imersa num campo magnético externo e é percorrida por uma corrente elétrica contínua.

Uma espira de corrente pode ser compreendida como um fio condutor formando um circuito elétrico fechado. Em geral este circuito tem o formato retangular, quadrado ou circular. O circuito da Figura 5 mostra uma espira retangular de comprimento a e largura percorrida por uma corrente elétrica I na presença de um campo magnético uniforme B, paralelo ao plano da espira e sentido de fora para dentro (entrando no plano hachuriado). Este campo magnético pode ser criado por um ímã colocado próximo a espira, como indicado anteriormente.

Em geral, esta espira tem os seus terminais ligados a um gerador que é o aparelho responsável por fornecer a corrente elétrica que irá percorrer a espira. Sempre que tivermos um fio conduzindo uma corrente elétrica na presença de um campo magnético, este fio ficara sujeito a ação de uma força magnética, como ilustrado na Figura 6. No caso da espira, esta força irá fazê-la girar, devido a ação do torque. 
O torque sobre a espira é dado por

$$
\vec{\tau}=I \vec{S} \times \vec{B},
$$

cujo módulo é $\tau=I S B \sin (\theta)$, onde $\theta$ é o ângulo entre o vetor $\vec{B}$ e a normal ao plano da espira, e $S=a b$ é a área definida pelos lados $a$ e $b$ da espira. É a variação do ângulo $\theta$, quando a espira gira, a responsável pela variação do fluxo magnético, como vimos na Seção 2 . Se em vez de uma única espira, tivermos várias espiras (como é o caso dos motores elétricos que estamos discutindo), temos uma bobina e, neste caso, o efeito do torque é multiplicado pelo número de espiras.

Na prática esta bobina está ligada a um dispositivo mecânico que irá transformar a energia elétrica da bobina em energia mecânica realizando algum tipo de trabalho - um motor elétrico.

\section{MOTOR ELÉTRICO}

Geralmente, a bobina acima referida é enrolada sobre um cilindro que é montado sobre um eixo capaz de girar sobre mancais (veja Figura 6). Neste eixo é colocado um par de contatos metálicos, sobre um cilindro isolante, em forma de uma casca cilíndrica que formarão os comutadores e que estarão ligados aos terminais da bobina. Outros dois contatos fixos (as escovas) fazem contato elétrico com estas cascas cilíndricas de modo a transferir energia elétrica para a bobina.

A ligação destes comutadores se dá de tal forma que em meia-volta da bobina, eles alimentam-na de maneira que a corrente circula num sentido enquanto que na outra meia-volta, com a inversão dos comutadores, a corrente na bobina circula na direção contrária.

Desta maneira, o comportamento mecânico do dispositivo pode ser explicado da seguinte maneira:

(a) quando se aplica uma diferença de potencial entre os comutadores, através das escovas circulará uma corrente elétrica num sentido tal que tende a movimentar a bobina em meia-volta, num sentido que depende justamente do sentido de circulação dessa corrente;

(b) ao girar, a bobina alcança a posição de repouso, meia-volta depois. Os comutadores estão agora em uma nova posição tal que os polos, positivo e negativo da fonte de alimentação encontram-se invertidos em relação ao caso anterior, e assim, a corrente inverte seu sentido de circulação e, consequentemente, ocorre a inversão do campo magnético;

(c) o resultado disso, é que a posição que a bobina alcançou não é mais a posição de repouso, já que surge uma nova força que tende a fazê-la continuar girando. A nova posição de repouso estará agora meia-volta adiante;

(d) a bobina gira de tal modo que alcança novamente a posição de repouso, mas ao chegar próximo dela, novamente entram em ação os comutadores e a corrente é novamente invertida. Uma nova posição de repouso aparece. Desta maneira, a nova posição de repouso estará novamente meia-volta a frente e a bobina continuará girando. É fácil perceber que a bobina nunca irá parar de girar enquanto houver disponibilidade de corrente para alimentar o circuito e obtém-se com isso o movimento giratório continuo da bobina. 


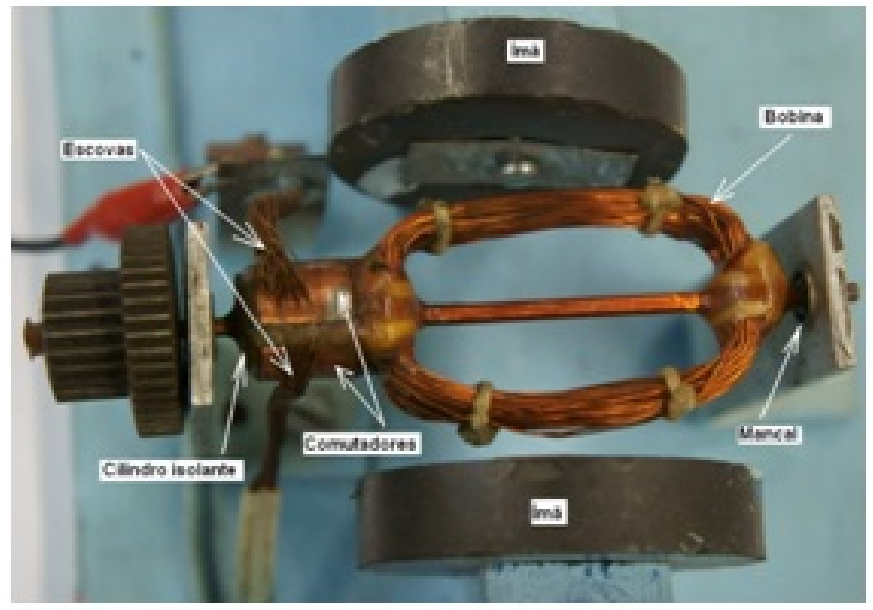

Figura 6: Motor de corrente contínua (didático), construído pelos alunos no laboratório de ensino.

A força que aparece no eixo desse tipo de motor depende de diversos fatores tais como o número de espiras da bobina, a intensidade do campo magnético, a intensidade da corrente, etc. Na Figura 6 pode-se ver o motor que foi construído em aula no laboratório didático. Uma discussão detalhada de como se pode montar um motor deste tipo, encontra-se, por exemplo, em (Gaspar, 2004).

Como pode ser visto em aula, o funcionamento de um motor elétrico de corrente contínua desse tipo, é bem simples. - Uma fonte de energia elétrica (pilhas, bateria, etc.) fornece corrente contínua a um comutador, uma peça de metal (bom condutor, no caso cobre) que está dividida em dois anéis, onde cada anel está ligado a um fio, que por sua vez, está ligado a um dos polos da bateria, um ao polo negativo e outro ao polo positivo.

Em contado com a superfície dos anéis do comutador estão dois fios de cobre que são extensões da bobina, a qual envolve um cilindro feito de material condutor. Este conjunto (cilindro envolto pela bobina) está na região de um campo magnético gerado por um ímã. Então, quando a corrente fluir pela bobina, criará um campo magnético que irá interagir com o campo magnético gerado pelo ímã, resultando em dois vetores de força magnética (veja Figura 6), de mesma magnitude e direção, porém com sentidos opostos e linhas de ação distintas, o que faz a bobina entrar em movimento. Esse movimento mecânico é transmitido através de eixos e poderá ser usado para realizar alguma coisa útil, como mover as pás de um ventilador caseiro, por exemplo.

Naturalmente, durante a montagem do experimento em sala de aula, pode se explorar ao máximo a possibilidade de interação entre o aluno e o objeto de aprendizagem, permitindo ao aluno, por exemplo, alterar o padrão de funcionamento do equipamento e observar variações nos efeitos e, desta forma, terem meios de estabelecer relações de causa e efeito. As possibilidades são diversas, mas um exemplo prático é a possibilidade de variar o sentido do campo magnético ao realizar a mudança da posição dos imãs o que traz como consequência a alteração no sentido de rotação do motor. 


\section{MODELAGEM E SIMULAÇÃO}

Neste trabalho o emprego dos softwares é como o de uma ferramenta auxiliar no processo de ensino e aprendizagem. Neste sentido, o computador é a ferramenta que possibilitará a ação do estudante, propiciando-lhe 'interagir' com o objeto de estudo, ao mesmo tempo em que é induzido a exercitar outras faculdades como construir, inovar, criar, modificar, resolver problemas, elaborar projetos e etc, até chegar a uma conceituação final coerente com a teoria do objeto ou fenômeno (da Silva, 2014).

O uso prático do computador se deu de duas formas distintas, com diferentes grupos de estudantes. No primeiro caso, executou-se a modelagem física do objeto de estudo, que no caso, o motor de corrente continua, é dada pelas equações do eletromagnetismo (Seção 2).

A modelagem computacional é criada, inserindo as devidas equações no software, primeiramente com a finalidade de realizar uma análise qualitativa do sistema, definir-se as variáveis do sistema para descrever o movimento, as dimensões da bobina, as condições para as direções dos vetores dos polos magnéticos, campo magnético, fluxo magnético entre outras. Mais explicitamente, usamos o software educacional Modellus que é controlado pelo modelo matemático, e no qual se insere todas as equações necessárias para a simulação. Esta etapa de modelagem, devido à complexidade da sua confecção, que envolve escolha das variáveis de interesse, aproximações intrínsecas ao modelo físico, e etc, ficou restrita aos estudantes mais experientes e bolsistas de graduação. Por exemplo, no caso da modelagem do motor de corrente contínua as variáveis relevantes foram: direção do campo magnético, largura da espira, comprimento do enrolamento, intensidade da corrente, número de espiras, tempo, resistência elétrica da bobina, direção da espira.É interessante observar que o fato da espira girar, mudando o angulo $\theta$ (sua direção), leva a torques que variam de forma senoidal, sendo nulo quando as linhas de campo são paralelas à normal ao plano da espira, e máximo quando elas são perpendiculares à normal desse plano.

A partir destas variáveis obtém-se uma série de dados usando as equações da Seção 2, como por exemplo campo magnético gerado pela espira, torque na bobina, fluxo magnético na bobina, força eletromotriz, potência útil, potência total, rendimento e outras. Possibilitando assim a realização de uma análise quantitativa do sistema. A Tabela 2 traz a lista de siglas utilizadas na modelagem e a Figura 7 mostra a tela de apresentação final da modelagem, onde a simulação poderá ser realizada e a animação visualizada.

A validação da modelagem é obtida comparando-se os resultados da simulação, com os dados experimentais obtidos do objeto concreto.

Uma vez concluída a modelagem o software é apresentado aos demais alunos que terão a liberdade de alterar os parâmetros que influenciam nos resultados e na animação. Através de cada mudança realizada nas variáveis, o sistema como um todo será influenciado, e então, os alunos poderão fazer análise qualitativa e/ou quantitativa do sistema, dependendo do nível/objetivo pretendido para a aula. A Figura 8 mostra os resultados obtidos após uma simulação.

Note que, desde que prevista na modelagem, a simulação permite ao professor responder e mostrar de forma prática, uma série de questionamentos e discussões que não seriam possíveis ous eriam difíceis de realizar no mundo físico, não virtual, como por exemplo, - o que acontece se a bobina tiver mais espiras? Se ela for maior ou menor? O atrito é relevante? Quais são as perdas? E se o imã for maior, menor? Enfim, diversos questionamentos em sala de aula podem ser simulados em tempo real e seus resultados 
Tabela 2: Tabela de siglas utilizadas na modelagem.

\begin{tabular}{|c|l|}
\hline Siglas & Significado \\
\hline $\mathrm{C}$ & Comprimento da espira \\
\hline $\mathrm{L}$ & Largura da espira \\
\hline $\mathrm{A}$ & Área da espira \\
\hline $\mathrm{N}$ & Número de espiras \\
\hline $\mathrm{i}$ & Intensidade de corrente \\
\hline $\mathrm{r}$ & Resistência \\
\hline $\mathrm{t}$ & Tempo considerado \\
\hline $\mathrm{Fi}$ & Densidade do fluxo do campo magnético \\
\hline $\mathrm{B}$ & Intensidade do fluxo do campo magnético \\
\hline $\mathrm{F}$ & Resultante das forças elétrica e magnética \\
\hline $\mathrm{T}$ & Torque gerado pelas forças \\
\hline $\mathrm{fem}$ & Força eletromotriz \\
\hline $\mathrm{U}$ & DDP gerada pela força eletromotriz \\
\hline $\mathrm{Pt}$ & Potência total \\
\hline $\mathrm{Pu}$ & Potência útil \\
\hline $\mathrm{N}$ & Rendimento \\
\hline
\end{tabular}
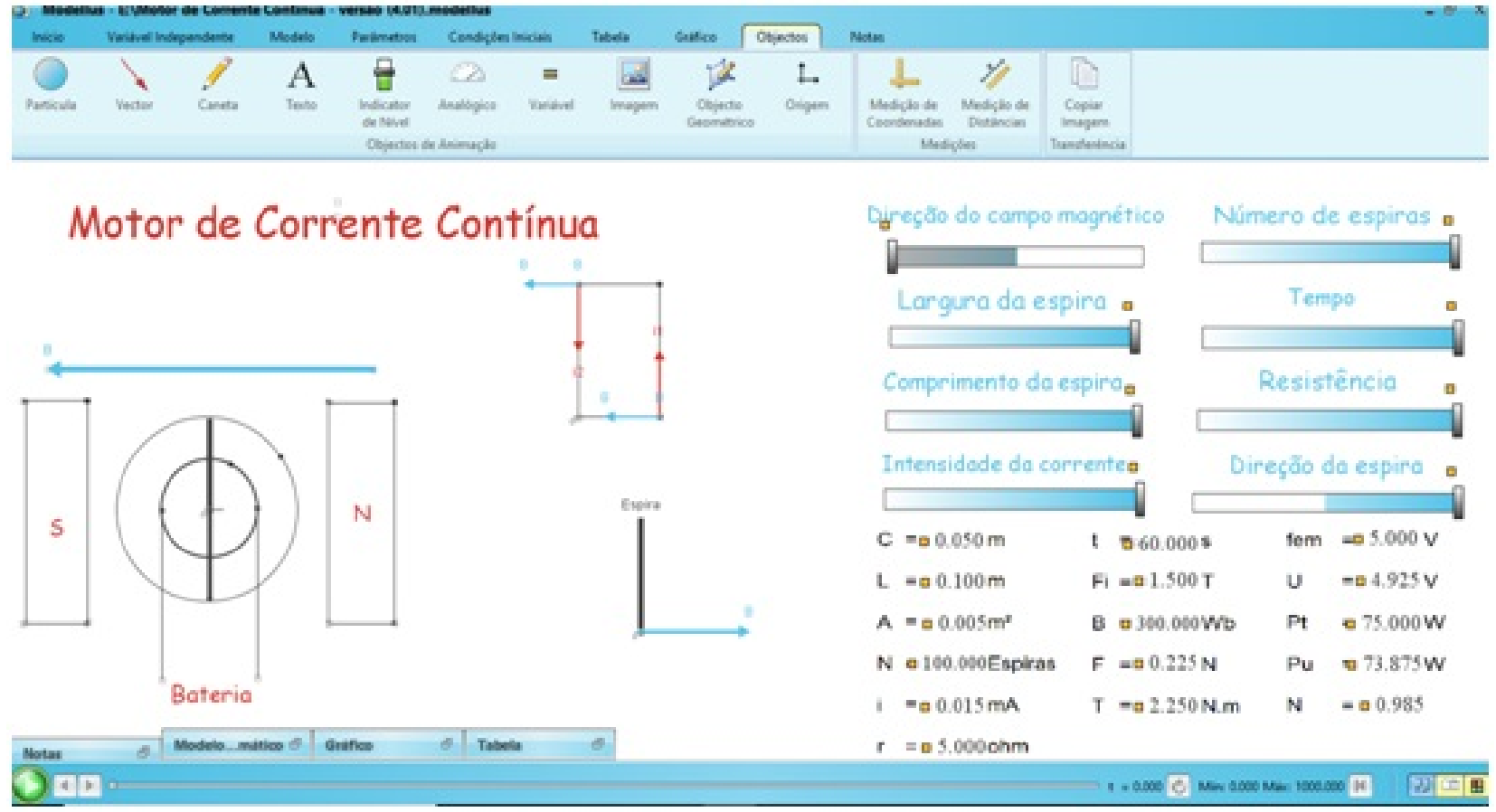

Figura 7: Tela de apresentação final da modelagem. 


\begin{tabular}{|c|c|c|c|}
\hline$C=\square 0.050 \mathrm{~m}$ & $\mathrm{t} \overline{\mathrm{\tau} 60.000 \mathrm{~s}}$ & fem & $=\square 5.000 \mathrm{~V}$ \\
\hline $\mathrm{L}=\square 0.100 \mathrm{~m}$ & $\mathrm{Fi}=\square 1.500 \mathrm{~T}$ & $u$ & $=\square 4.925 \mathrm{~V}$ \\
\hline$A=\square 0.005 \mathrm{~m}^{2}$ & B 口 $300.000 \mathrm{~Wb}$ & $\mathrm{Pt}$ & $\square 75.000 \mathrm{~W}$ \\
\hline$N \square 100.000$ Espiras & $F=\square 0.225 \mathrm{~N}$ & $\mathrm{Pu}$ & $\neg 73.875 \mathrm{~W}$ \\
\hline $\mathrm{i}=\square 0.015 \mathrm{~mA}$ & $\mathrm{~T}=\square 2.250 \mathrm{~N} \cdot \mathrm{m}$ & $\mathrm{N}$ & $=\square 0.985$ \\
\hline$=\square 5.000 \mathrm{ohm}$ & & & \\
\hline
\end{tabular}

Figura 8: Quadro de dados de uma simulação típica (na notação acima, os pontos correspondem à notação decimal).

visualizados na forma de animação, socializando dúvidas e conclusões.

\section{CONSIDERAÇÕES FINAIS}

A ideia do estudo do motor de corrente contínua foi concebida após os alunos, participantes do Projeto Jovens Talentos, relatarem que nas suas respectivas unidades escolares, os professores estavam abordando o eletromagnetismo como tema das suas aulas. Esse projeto é desenvolvido conjuntamente por professores e alunos. Os questionários de avaliação, as opiniões dos alunos e o passo a passo da montagem do equipamento foram divulgados fora daqui (Ferreira, 2017) como parte do trabalho de extensão.

A metodologia proposta substitui as aulas expositivas por atividades práticas, engendradas para levar os estudantes a projetar, construir, gerar e observar fenômenos físicos, refletir sobre eles e discutir com seus colegas e com o professor até que o objeto, o conceito em foco, seja efetivamente aprendido. A abordagem realizada tem sido chamada de aprendizagem ativa e encontra-se fundamentada no trabalho de diversos autores que mostram que as interações mútuas entre os estudantes, e entre eles e os professores, são fundamentais para uma boa formação (Machado et al., 2014; Valente 1998).

As atividades práticas se desenvolvem num processo totalmente dinâmico, e são mecanismos que aprimoraram os processos de ensino e aprendizagem, tornando-os mais participativos, interativos e socialmente realizados, atraindo significativamente a atenção dos alunos para o objeto de estudo e as ciências envolvidas.

Outro aspecto a ser ressaltado é o papel dos docentes neste novo processo de ensino. O professor estabelece em conjunto com a classe, o projeto de montagem do dispositivo que será o instrumento de aprendizagem. Nesse ponto, estabelece equipes de trabalho e sugere pesquisas, contextualiza, mostra as aplicações etc... O dispositivo é montado em sala de aula com a participação direta dos estudantes e lá é testado. Com o dispositivo em funcionamento, sintetiza-se a física envolvida e lapidam-se os conceitos, muitos dos quais podem ser imediatamente testados no experimento real, ou no computador uma vez que o software permite a simulação do mesmo dispositivo.

No caso de apenas o laboratório virtual estar disponível, os professores utilizam o computador como uma ferramenta para a realização de atividades, criar projetos que motivem ao mesmo tempo em que desafiam os aprendizes a buscarem novas soluções. Nesse contexto, explora-se o trabalho do professor 
como um mediador entre os alunos e o saber, ao mesmo tempo em que o aluno também utiliza o computador como uma ferramenta de aprendizagem que é dotada de uma linguagem dinâmica, autoexplicativa, que lhe permite perceber as relações existentes entre os diversos fenômenos naturais, e como os conhecimentos teóricos apropriados aplicam-se no cotidiano.

A diferença dessa proposta está centrada na ressignificação das TIC, que deixam de ser novos meios para executar velhas atividades e passam a ser ferramentas que, além do acesso à informação, facilitam a realização de experiências que em outros tempos se mostravam impossíveis nos ambientes escolares.

A abordagem cria uma aula interativa ao utilizar novas tecnologias disponíveis, e concretiza um modelo didático-pedagógico não mais restrito a um ensino essencialmente livresco.

No caso em questão, o computador esteve presente em dois momentos distintos. No primeiro, com um grupo seleto de alunos (graduandos em física) desenvolvemos as modelagens e o software para as simulações. Esta atividade se mostra bastante importante pois confere ao futuro docente alguma autonomia para desenvolver novas modelagens em outras áreas da física. Mais ainda, ele não se apropria apenas do conhecimento, mas aprende uma maneira de exercer sua futura profissão, quando então, será capaz de desenvolver e usar softwares educacionais em suas aulas, o que, como já mencionamos, favorecem as inter-relações e o intercâmbio crítico de ideias entre os indivíduos em sala de aula.

No segundo momento o software, já preparado para a simulação, foi aplicado em aula para os alunos do ensino médio. Os primeiros alunos que colaboraram na modelagem e no desenvolvimento do software exerceram a função de monitores. Os resultados foram extremamente animadores.

Naturalmente, a abordagem teórica no ensino médio não é a apresentada na Seção 2. Nesse nível, a maioria dos conceitos foi introduzida de forma 'empírica' sendo os dados obtidos no laboratório real, como discutido na Seção 4, ou levantados no laboratório virtual alterando-se os parâmetros, construindo gráficos e observando como o sistema irá se comportar em função da alteração numérica das variáveis, como descrito na Seção 5.

Aparentemente restrita ao ensino presencial, as atividades práticas, tal como pensadas por Piaget, podem ser também realizadas no ensino à distância, através da simulação computacional obtida pela modelagem do problema-objeto. Com efeito, a internet pode promover o intercâmbio e a troca de ideias, dúvidas e sugestões entre os participantes da rede (professor, aluno, convidado...) (Alvez \& Nova, 2003), agora não se limitando aos fisicamente presentes. Assim, o uso de software educacional, especialmente modelado para a simulação de um problema físico, pode recontextualizar o conceito de atividade pratica, expandindo-o ao ambiente virtual, e então, viabilizar uma aula na qual o aluno pode participar e interagir à distância, dando lugar a um tipo de aprendizagem ativa. A possibilidade de a aprendizagem ativa ser realizada num computador amplia suas possibilidades para os cursos mais avançados da física, para os quais não existem laboratórios didáticos, ou eles seriam impossíveis, como é o caso dos cursos de mecânica quântica e cosmologia, respectivamente.

A recontextualização das atividades práticas em seus pressupostos e sua utilização na prática pedagógica consiste numa proposta com foco na realização de atividades experimentais em sala de aula, e no laboratório virtual com uso das TIC, no computador. Essa metodologia possibilita a discussão de conteúdos que expliquem a natureza e deem oportunidades ao indivíduo de adquirir/desenvolver capacidades para atuar nesse mundo. Embora a disciplina considerada tenha sido física, as discussões sustentadas por uma atitude crítico-reflexiva se aplicam à maior parte (se não a todas) das disciplinas. 
Revista do Professor de Física • Brasília, vol. 2, n. 2 • 2018

Finalmente, gostaríamos de chamar a atenção do leitor para o fato de que a metodologia ativa utilizada não é a de instrução pelos pares que pressupõe uma sondagem de conhecimentos prévios dos estudantes. Embora contenha elementos de instrução por pares nos trabalhos de grupo, a metodologia ativa utilizada é a proposta originalmente por William James (1890-1971) e John Dewey (1922-1979) no final do século XIX, e busca um método de ensino focado no aluno. A aprendizagem ativa ocorre quando o aluno interage com o assunto em estudo e é estimulado a construir o seu conhecimento, ao invés de receber passivamente a informação do professor.

\section{Referências}

[1] ALVEZ, L.; NOVA, C. Educação a Distância: uma nova concepção de aprendizagem e epistemologia. Futura, (2003).

[2] BRASIL, Ministério da Educação. Secretaria de Educação Fundamental, Parâmetros Curriculares Nacionais: Ciências Naturais, 2. ed. Rio de Janeiro: DP\&A, (2000).

[3] COQUIDÉ, M. Ensaio, 10, 1 (2008).

[4] CHAIB, J.P.M.C.; ASSIS, A.K.T. Rev.Bras.Ens.Fis., 29, 41 (2007).

[5] DA SILVA, C.E., SANTIAGO, A.J., MACHADO, A.F.; DE ASSIS, A.S, Eletromagnetismo Fundamentos e Simulações, Pearson Education do Brasil, (2014).

[6] DEWEY, John. L'école et l'enfant. 2a. edição. Neuchatel, Suíça;Paris, França: Éditions De lachaux, 1922. A Filosofia em reconstrução. São Paulo: Editora Nacional, 1958. . Mi credo pedagógico. In Natorp, Dewey, Durkheim. Teoría de laeducación y sociedad. Introducción y selección de textos. Fernando Mateo. 1a. reimpressão. Buenos Aires: Centro Editor de América Latina, 1978, p. 55-65. . Democracia e Educação. 4a. Edição. São Paulo: Companhia Editora Nacional, 1979.

[7] ERN, E.; AIRES, J.A. Contribuições da história das disciplinas escolares para a história do ensino de ciências. Disponível em: $<$ http://www.seer.ufrgs.br/index.php/educacaoerealidade/article/viewFile/6662 /3978>. Acesso em: 10 dez. 2014.

[8] DE ANDRADE, M.L.F.; MASSABNI, V.G. Ciênc.educ, 17, 835 (2011).

[9] FERREIRA, Y. P. U. M.;MACHADO A., SILVA, C., SILVA, L.P.C. O Uso do Software Educacional Modellus como InstrumentoComplementar no Ensino de Física: Analisando um Gerador deCorrente Contínua. Revista Interagir: pensando a extensão - UERJ (2017):130-148.

[10] GASPAR, A. Cad. Bras. Ens. Fís., 21, 188 (2004).

[11] HENRIQUES, V.B., PRADO, C.P.C. e VIEIRA, A.P. Rev. Bras. de Ens. Fís., 36, 4001 (2014). 
[12] JAMES, William. The principles of Psychology (New York, 1890), vol. II, cap. 28. In: HERRNSTEIN, R.J.; BORING, E.G. (orgs.). Textos básicos de história da psicologia. Tradução de Dante Moreira Leite. São Paulo: Editora Herder; Editora da Universidade de São Paulo, 1971, p. 477-491. . TALKS TO TEACHERS ON PSYCHOLOGY AND TO STUDENTS ON SOME OF LIFE'S IDEALS. New York: Henry HoltandCompany, 1899 (http://www.uky.edu/ eushe2/Pajares/JamesTalksToTeachersFirstEdition.pdf - Acesso em 16/10/2014). __ _. Palestras pedagógicas. Trad. de Theodoro de Moraes. São Paulo: Typ. Augusto Siqueira \& C., 1917.

[13] KRASILCHIK, M. Prática de ensino de biologia ,4. ed. São Paulo: EDUSP, (2004).

[14] MACHADO, A.F., SANTIAGO, A.J., SILVA C.E., e SIMÕES, D. em Simões D. \& García, F. (org.), A pesquisa científica como linguagem e práxis. Publicações Dialogarts, RJ, (2014).

[15] PIAGET, J. Psicologia e pedagogia, Rio de Janeiro: Forense, (1972). , Psicologia e epistemologia por uma teoria do conhecimento, 2. ed. Rio de Janeiro: Forense Universitária, (1978).

[16] PINO, P. V.; OSTERMANN, F.; MOREIRA, M.A., Rev. Bras. Pesq. Ed. Ciên., 5, 5-14, (2005).

[17] SANTIAGO, A.J., SILVA, C.E.; MACHADO, A.F.; WASHINGTON, M.G. Jour. of Soc. Science, 3, 8 (2015).

[18] SKINNER, B. F. Tecnologia do Ensino. Capítulo II - A Ciência da aprendizagem e a arte de ensinar. Herdere e Edusp. p 22 (1972).

[19] VALENTE, J. A. Computadores e Conhecimento: representando a educação. Gráfica Centra UNICAMP (1998).

[20] WENTWORTH, S.M. Eletromagnetismo Aplicado, Bookman (2009).

[21] ZANON, D.A.V. e FREITAS, D.A. Ciências \& Cognição, Rio de Janeiro, 10, 93 (2007). 